\title{
A STUDY ON DIFFERENT PELLET FORMATION TECHNIQUES AND ITS EVALUATION PARAMETERS-A REVIEW
}

\author{
REHANA BEGUM A.*, GANESH N. S., VINEETH CHANDY \\ Department of Pharmaceutics, T. John College of Pharmacy, Bangalore \\ Email: rehubph@gmail.com
}

Received: 14 Nov 2018, Revised and Accepted: 20 Feb 2019

\begin{abstract}
This review article deals with the various pelletization techniques utilized in the pharmaceutical industry for spheroidal particle production i.e., pellet for mainly oral administration which can be further formulated into several other dosage forms such as tablets, capsules or can be administered as such. Now-a-days oral administration has become the most versatile, convenient and common route of drug administration which ultimately focuses on patient compliance. The technique which is setting horizon in pelletization is "Extrusion Spheronization" because of its simple and easy steps involved in pellet production in a faster way. This review also includes the characterization and evaluation of pellets to ensure its quality, safety and efficacy to give out the required therapeutic activity after administration.
\end{abstract}

Keywords: Different pellet formation techniques, ITS Evaluation Parameters

(C) 2019 The Authors. Published by Innovare Academic Sciences Pvt Ltd. This is an open access article under the CC BY license (http://creativecommons.org/licenses/by/4.0/) DOI: http://dx.doi.org/10.22159/ijcpr.2019v11i2.33020

\section{INTRODUCTION}

\section{Pellets}

In the pharmaceutical industry, pellets are simple small free-flowing spherical particles formed by agglomeration of fine powder or granules, which can be given in the form of tablets and capsules for various disease conditions, although tablets are more convenient than capsules. The size range of pellet size is of $0.5-2.0 \mathrm{~mm}$ [1].

Flexibility of pellets in development of dosage form [2]

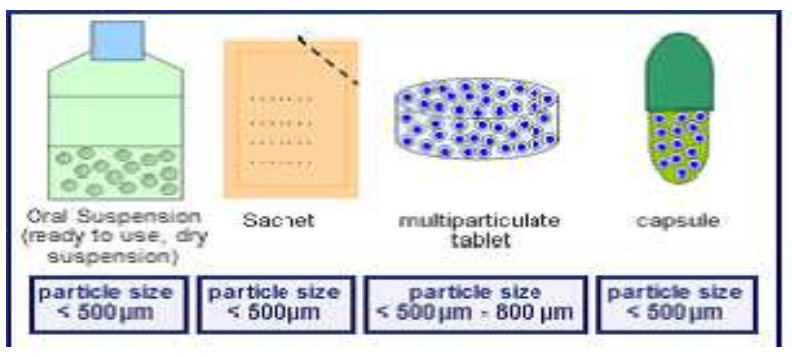

\section{History of pellets [3]}

In the 1950's, pellets came into existence in the field of "Pharmaceutical Industry" with an impact of sustain release dosage form. In terms of formulation, processing methods and equipment used were faster, cheaper and more efficient. It can also be used for sustained release of active constituents.

Properties of pellets

Uncoated pellets [4]

It should have high physical strength and integrity with uniform shaped smooth pellets along with improved flow properties with an optimum size range of 600 and $1000 \mu \mathrm{m}$ provided with good hardness and low friability.

\section{Coated pellets [5]}

Along with uncoated properties of pellets, coated pellets maintains the active ingredient to give the uniform size of final dosage form within its standard limits, and also gives desirable drug release studies.

Formulation aspects of pellets [6]

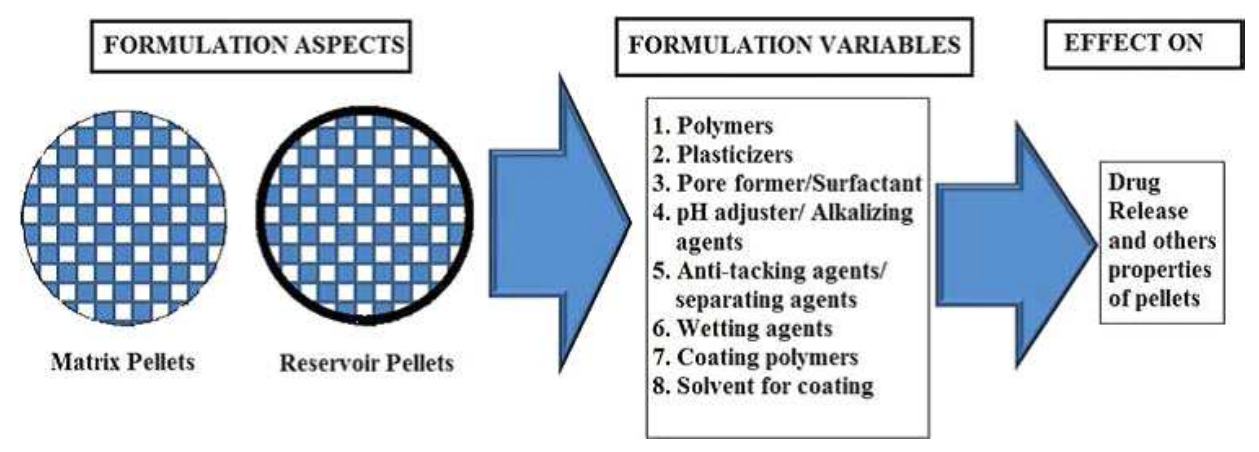

\section{Advantages of pellets}

Technological advantages [3]

- Pellets show excellent flowing properties, due to its elegance.
- Extrusion Spheronization technique gives uniformity of dose with excellent accuracy.

- $\quad$ Pellets provide safety by preventing dust formation which can cause health issues because of fine powders due to its dust explosives. 
- The product appearance is improved.

- The efficacy of product is improved due to the safety of the active ingredient

- It shows less abrasion, decreased friability with uniform size.

\section{Therapeutical advantages [7]}

- Pellets prevent from dose dumping and cause lesser side effects when prepared in sustained release form.

- $\quad$ They disperse freely in gastric intestinal fluids due to small in size, which gives a larger area for drug absorption and reduces peak plasma fluctuation.

- $\quad$ Reduces accumulation of drugs which are irritant to gastric mucosa.

- The incompatible drugs or recipients can be prepared as a single dosage form.

- Used for masking the bitter taste of unpalatable drugs.

With its large number of advantages, however, there are a few disadvantages

\section{Disadvantages of pellets [8]}

- Sometimes pellets are too rigid in nature which is difficult to compress as a tablet, therefore have to be encapsulated into a capsule.

- The process of pelletization is a highly sophisticated method because specialized equipments are used.

- The cost of manufacturing is high.

- It involves number of formulation variables and process variables which leaves the manufacturing process complicated.

\section{Pharmaceutical applications of pellets [9]}

- $\quad$ Pellets in fast dissolution system: For immediate release like fast disintegration and fast dissolving pellets can be prepared for conventional oral drug delivery system.

- Pellet combination as control release drug delivery System: Different pellets of incompatible chemicals can be combined in the same dosage form.

- Pellets for Inhalation: Non-irritating soft pellets are designed for inhalation with a maximum particle diameter of approximately 1 $\mathrm{mm}$ in size for treating respiratory disorders.

- $\quad$ Pellets as Implants: Polymeric spheroidal particles can be used as implants for release of "Active Pharmaceutical Ingredients" over a longer period of time. Several methods of pelletization are used for pellet implant production, but widely used is an extrusion.

- $\quad$ Pellets as Solid Self Emulsifying Drug Delivery System: Used for lower aqueous solubility drugs to improve the in vivo behavior of drug by achieving dose proportionality by reducing inter, intrasubject variability.

\section{Pelletization technique [10]}

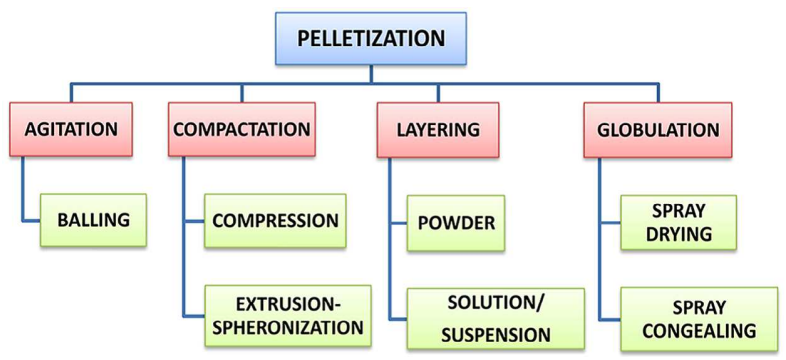

\section{Agitation [10]}

Agitation involves the conversion of finely divided particles into spheroidal particles by the addition of required liquid by a continuous rolling or tumbling motion. The liquid can be added at the beginning of the process, or during the agitation process. Pans, discs, drums or mixers may be used to produce pellets by the balling process. It is the oldest and less efficient technique for production of pellets.

\section{Balling [9]}

It can be done either by adding the required volume of liquid into powder or by applying a high temperature. Spherical agglomeration can be divided into two categories, such as liquid-induced agglomerations and melt-induced agglomerations. Instruments like conventional horizontal drum pelletizers, inclined dish pelletizers or tumbling blenders, rotary fluid-bed granulators. This technique is popularly used in iron ore and fertilizer industries. The rate and extent of agglomeration formation depend on formulation variables such as particle size, the degree of liquid saturation, viscosity of liquid phase and solubility of powder.

\section{Compactation [10]}

Agglomeration of drug particles or granules takes place in presence of pressure which gives out well-defined shape and size of pellet.

\section{Compression [4]}

Blend of active ingredients and number of excipients are compressed with the aid of pressure to give out defined shape and size of the pellet.

\section{Extrusion-spheronization [11]}

Extrusion Spheronization is used to produce spheroidal structure or pellets of uniform size. It involves multiple processes such as wet mass extrusion followed by Spheronization to produce matrix pellets or spherical particles or beads. Apart from medical field, it has greater application in other fields such as agrochemicals, detergent additives, sweeteners, food; etc. It is the most commonly used method for pellet formation. "Spheronization" is a primarily used for oral drug delivery system.

\section{Layering [13]}

Pellet formation by layering involves the deposition of successive layers of drug molecules from dry powder or granules, suspension, a solution of drug particles.

\section{Powder layering technique [8]}

Various steps involved in this technique are as follows.

- $\quad$ Sifting/milling

- Loading of non-pareil seeds

- Drug coating

- Drying

- $\quad$ Sizing

- Functional coating

- Encapsulation

Solution/suspension layering technique [12]

Various steps involved in this technique are as follows.

- $\quad$ Mixing/milling

- Loading of non-pareil seeds

- $\quad$ Drug coating

- Drying

- $\quad$ Sizing

- Functional coating

- Encapsulation

\section{Globulation [3]}

It is also known as droplet formation, it contains two process, spray drying and spray congealing. It works by atomization of hot melts, suspensions or solutions to form pellet particles. 


\section{Spray drying [3]}

In this process, drug substances in solution or suspension are sprayed with or without excipients into hot stream of air to generate dry spheroids. When atomized droplets come in contact with hot air, evaporation of the application media takes place, this drying process continues through a series of stages where the viscosity of the droplets continuously increases until the entire application medium is evaporated and finally solid particles are obtained. The spraydried powder particles are homogenous with uniform size. The design and operation of the spray drier can improve the characteristics of final pellet such as particle size, particle distribution, bulk density, porosity, flow ability, moisture content, and friability.

\section{Spray congealing [9]}

It is another globulation technique, where a melt material is sprayed and pellet formation occurs. And it solidifies through a fluid stream of gas or liquid material at a suitable temperature lower than the melting point of the carrier or drug molecule. This method is best suitable for coating of beads and also for small size beads.

\section{Extrusion-spheronization [10]}

The extrusion Spheronization is a common technique and widely used method for uniform size pellet production with multiple steps. This process was first devised by Reynolds in the year 1970 and also Conine Hadley gave his contribution to the technique.

It is multiple process of wet mass extrusion which further pursued by spheronization step to produce matrix pellets or beads of spheroids, and mainly used for the production of multiple particle for oral sustained drug delivery system. The extrusion operation densifies the material to saturation point while spheronization is only a shaping process and drying operation finalizes the textural characteristics of the product by densifying the medium through induced shrinkage [4].

It is a worldwide using process due to its simple and fast processing technology.

\section{Pellet formation by extrusion spheronization [14]}

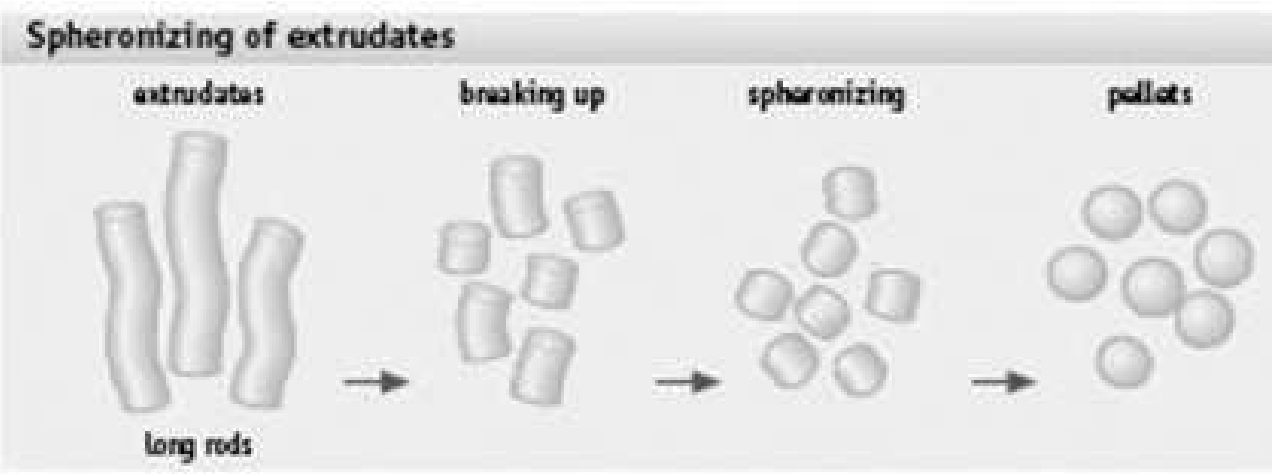

Mechanism of pellet formation by extrusion spheronization [14]

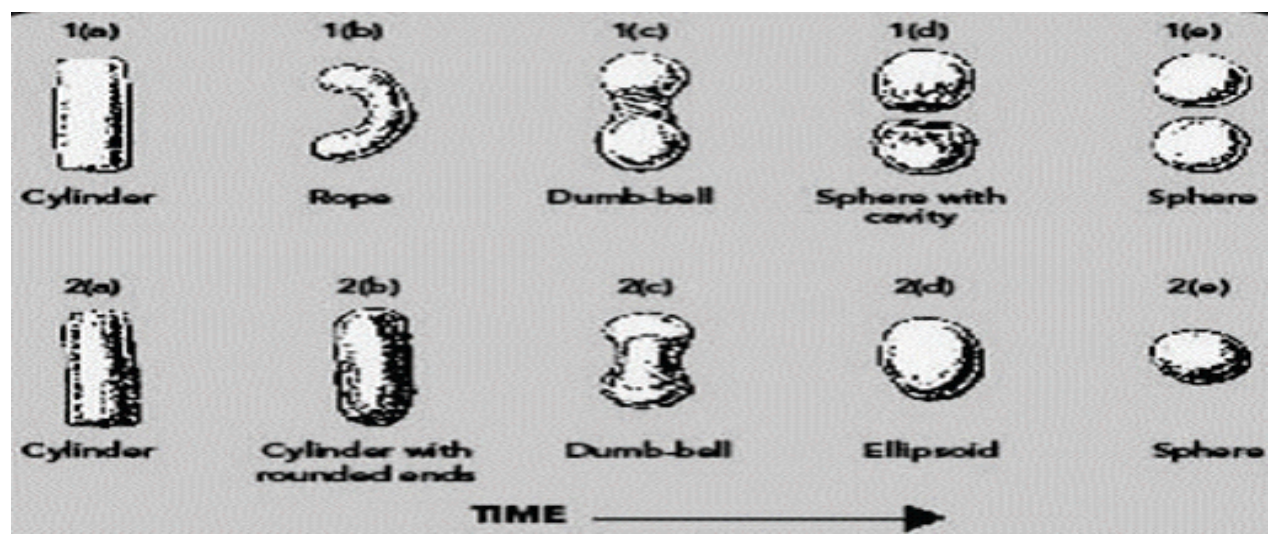

\section{Process of extrusion spheronization [4]}

Extrusion spheronization follows mainly four steps, they are as

1) Preparation of the wet mass (granulation)

2) Shaping the wet mass into cylinders (extrusion)

3) Breaking up the extrudate, rounding the particles into spheres (spheronization)

\section{4) And drying of pellets}

\section{Preparation of the wet mass (Granulation)}

It involves, preparation of the plastic mass of the material with different types of granulator's usage to perform the mixing of the powder blend and the granulation liquid. The most common and simple granulators used are the planetary mixer, high-shear or sigma blade mixer, etc. The wet granulation process plays an important role in extrusion-spheronization. With the Twin Screw Extruder (TSE), it allows the possibility of wet granulation to run continuously.

\section{Shaping the wet mass into cylinders (Extrusion)}

The prepared plastic mass undergoes the extrusion process in which pressure is applied to a mass of particles until it flows out through an orifice to produce the extrudates. The extrudate length might vary from each other, depending on the physical characteristics of the materials extruded. Extrusion is performed using five main classes of extruders: screw, sieve and basket, roll, and ram extruders. Details for all types of the extruder are given in table 1 [10]. 
Types of extruders with schematic representation [10]

Screw Extruder: A) Axial screw extruder

B) Radial screw extruder

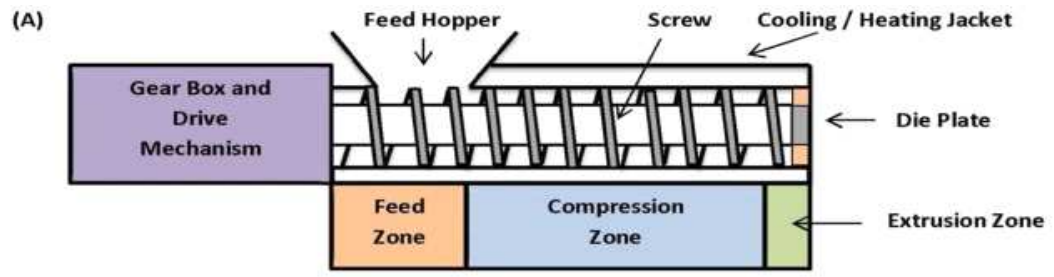

(B)

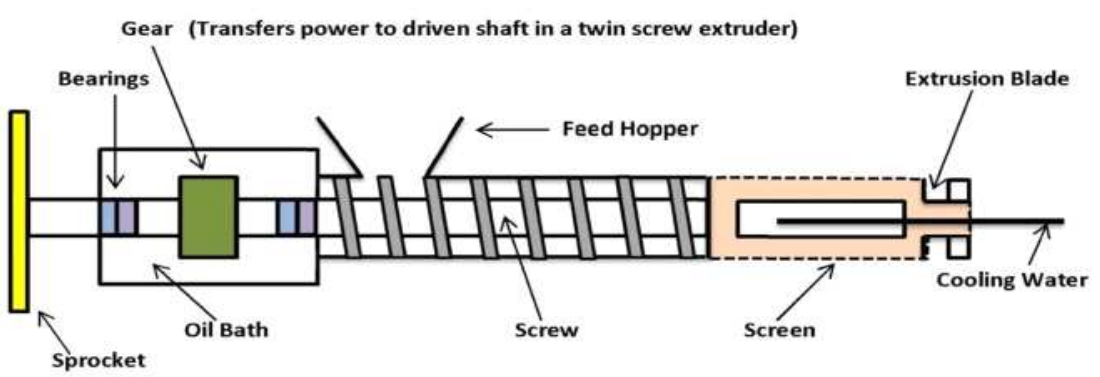

A) Sieve extruder

B) Basket extruder

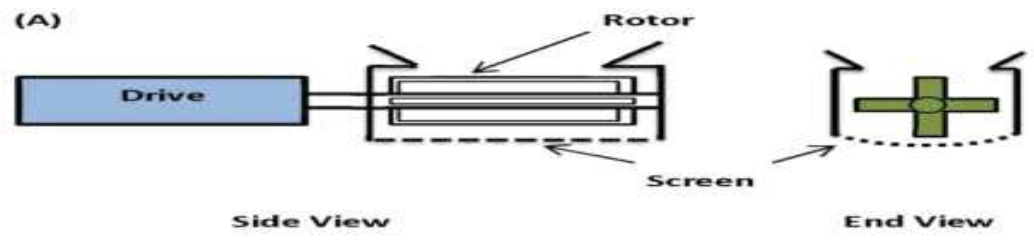

(B)

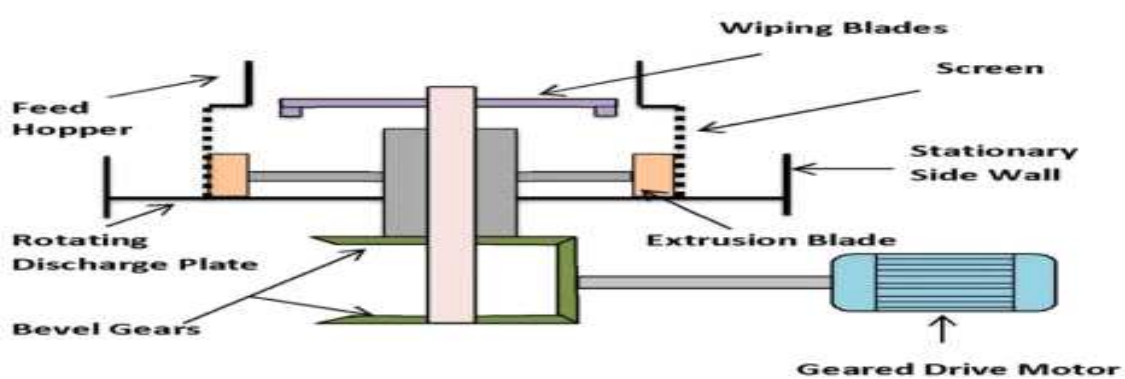

Table 1: Details for all types of the extruder are given in table

\begin{tabular}{|c|c|c|}
\hline Type of extruder & Mechanism & Comment \\
\hline Screw extruder & $\begin{array}{l}\text { Utilizes a screw to develop the necessary } \\
\text { pressure to force the material to flow } \\
\text { through uniform openings }\end{array}$ & $\begin{array}{l}\text { a) Axial: Screen is placed at the end of the screw, perpendicularly with the axis } \\
\text { of the screw } \\
\text { b) Radial: Screen is placed around the screw, discharging the extrudate } \\
\text { perpendicularly to the axis of the screw }\end{array}$ \\
\hline Sieve extruder & $\begin{array}{l}\text { A rotating or oscillating arm presses the } \\
\text { damp material through a sieve }\end{array}$ & Extrudate falls vertically from the sieve plate \\
\hline Basket extruder & $\begin{array}{l}\text { Similar to sieve extruders, except that the } \\
\text { sieve or screen is part of a vertical } \\
\text { cylindrical wall }\end{array}$ & Extrudate formed in the horizontal plane \\
\hline Roll extruder & $\begin{array}{l}\text { Roll extruders operate by feeding material } \\
\text { between a roller and a perforated plate or } \\
\text { ring die }\end{array}$ & $\begin{array}{l}\text { Type 1: A ring rotates around one or more rollers installed inside the } \\
\text { cylindrical die chamber, each of which rotates on its stationary axis. } \\
\text { Type 2: The roller or rollers are mounted on the outside of the ring die and } \\
\text { material is fed from a hopper occasionally with a screw, into the region } \\
\text { between the roller and the die. } \\
\text { Type 3: Rollers are positioned above and roll along the surface of a flat, } \\
\text { stationary die plate. }\end{array}$ \\
\hline Ram extruder & $\begin{array}{l}\text { A piston riding inside a cylinder or channel } \\
\text { is used to compress material and force it } \\
\text { through an orifice on the forward stroke }\end{array}$ & $\begin{array}{l}\text { Extrusion forces recorded with the ram extruder are always greater and force } \\
\text { necessary to extrude the wet mass through the ram extruder decreases as the } \\
\text { quantity of water added increases }\end{array}$ \\
\hline
\end{tabular}




\section{A) Internal roller}

B) Roller external to die

C) Roller on the flat die plate

(A)

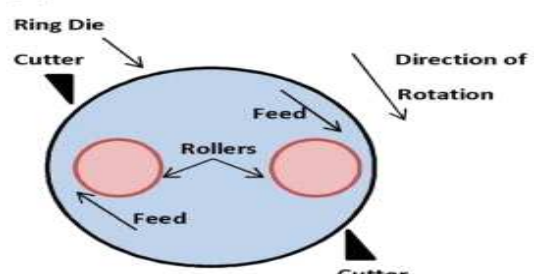

(c)

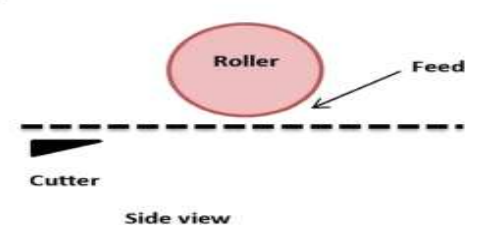

(B)

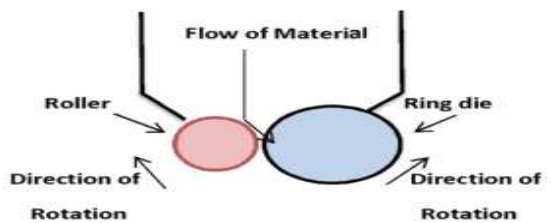

Rotation

Rotation

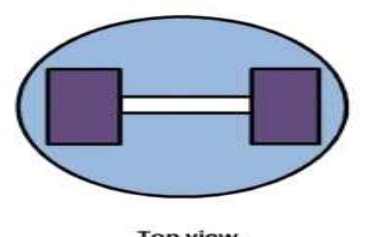

\section{Ram extruder}

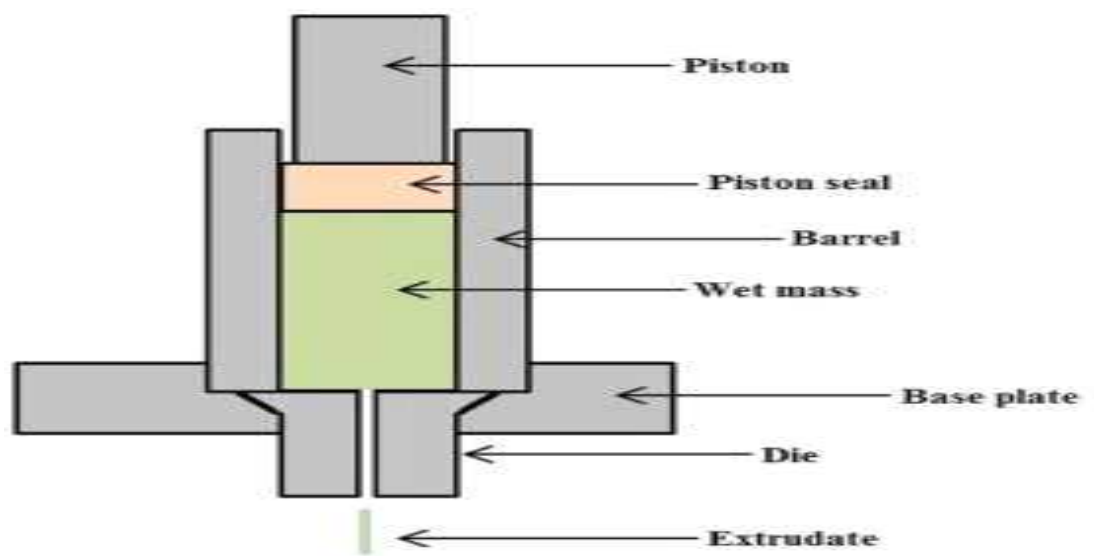

\section{Spheronization [12]}

In this process, the extruded cylindrically shaped particles are uniformly broken into a particular length which gradually leads to the formation of spherical shapes, thus shaping process is due to plastic deformation. Extrudates are first broken into nearly uniform lengths, all three dimensions of agglomerate shape are determined and spheres with uniform diameter are obtained. In spheronization process, different stages can be distinguished depending on the shape of the particles, i.e., starting from a cylinder over a cylinder with rounded edges, dumbbell shape and elliptical particles to eventually perfect spheres.

\section{Schematic diagram of spheronizer}

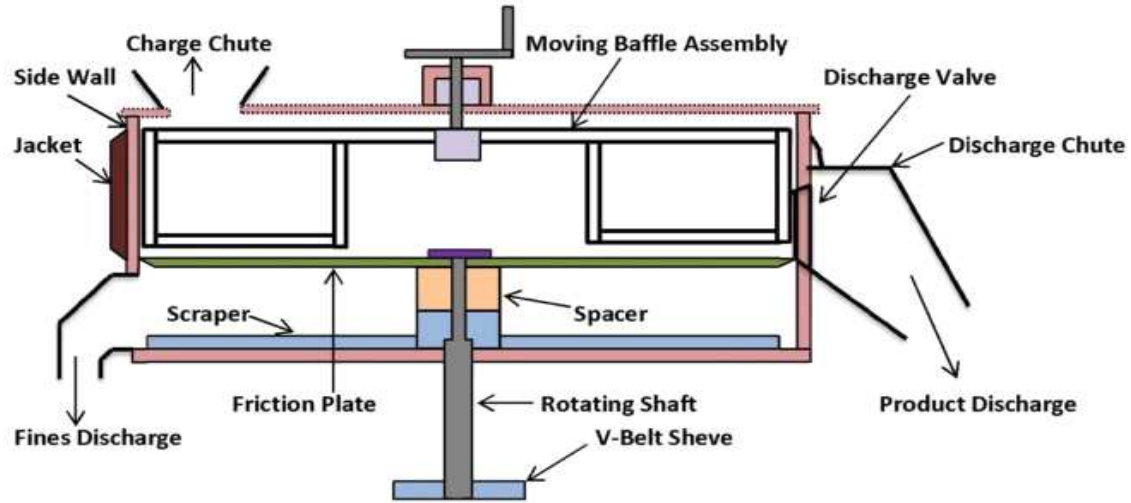

\section{Spheronizer [15]}

It is an instrument or a device consisting of a vertical hollow cylinder with a horizontal rotating disk i.e.; friction plate situated inside the cylinder. The extrudates are charged onto the rotating plate and broken into short pieces by contact with the rotating disk, collisions between particles and also collisions with the wall device. Mechanical energy is supplied by the spinning of the rotating disk which is converted into kinetic energy in the form of a mechanically fluidized bed. Continuation of this process causes the extrudate to 
deform slowly into a spheroidal structure. The rotating disk has a grooved surface to increase the frictional forces. There are two types of grooves available based on geometry, they are "cross-hatch geometry" where the grooves are formed from right angles and "radial geometry "which uses a radial pattern.

\section{Factors affecting pelletization technique [4]}

- Rheological characters.

- Moisture content.

- The composition of granulating fluid.

- Physical properties of the material used.

- The speed of the spheronizer equipment.

- The solubility of excipients and drug in granulating fluid.

- Drying temperature and drying technique parameters.

- Extrusion screen.

\section{Characterization and evaluation of pellets}

The prepared pellets must go through various parameters for characterization and evaluation of pellets.

\section{Characterization of pellets as follows}

\section{Particle size analysis [16]}

The particle sizes of the formed pellets are to be measured using an optical microscope with ocular and stage micrometer where the particle size distribution can be calculated. The 'Wesmox model' with a resolution of $45 \mathrm{x}$ may be used.

The particle size distribution study can also be done by 'Sieve Analysis' technique by using a set US standard sieve of different mesh size known as different sieve numbers such 14,16,18,22 and 44 with a pellet of the load of $10 \mathrm{gm}$. The sieve set is to be mechanically shaken for $10 \mathrm{~min}$, total net weight of pellets retained on each sieve was determined and these values are used for calculating particle size distribution.

\section{Micrometric properties}

- The angle of repose [17]: Angle of repose is used to know the pellet flow property by using a fixed funnel method. The radius ( $r$ ) of the pellet pile formed and height of the pellet pile $(\mathrm{h})$ is determined. The angle of repose for the pellet sample is calculated using the formula:

$$
\theta=\tan -1(\mathrm{~h} / \mathrm{r})
$$

Where ' $r$ ' is the radius of the pellet pile formed an ' $h$ ' is the height of the pellet pile.

- Carr's index [17]: It is a dimensionless parameter, which proves to be useful to the same degree as the angle of repose values for determining the flow property.

Apparent bulk density was determined by pouring the bulk samples into a graduated cylinder. Tapped density can be determined by placing a graduated cylinder containing a known mass of powder on a mechanical tapper apparatus (Electro lab tap density tester). Carr's index can be calculated by using the equation given below:

\section{- Carr's index=Tapped density-Bulk density/Tapped density}

Hausner's ratio was measured by the ratio of tapped density to bulk density.

\section{- Hausner's ratio [17] = Tapped density /Bulk density}

- Friability (F) [17]: Friability test for pellets takes place by using known mass pellets particle size ranging from 1000 to $1410 \mu \mathrm{m}$ as (WO) placed in an apparatus called as "Roche friabilator" where the procedure involved is a simplest one by maintaining $25 \mathrm{rpm}$ for a time period of $4 \mathrm{~min}$. After completion of the required time period, the pellets are removed from the apparatus in a sterilized manner and further subjected to know the weight of the pellets as final weight or weight after 100 rotations i. e, $4 \min (\mathrm{W})$ of time and the friability was calculated by using the equation mentioned below:

- Friability $\%=[1-\mathrm{W} / \mathrm{W} 0] \times 100$

Where, WO is the initial weight and $W$ is the weight after100 rotations.

The friability test is performed on the formed pellets to ensure the ability of mechanical strength to withstand the property of strength where lower the friability value indicates good mechanical strength of the spheroids.

- Pellet sphericity test [17]: The pellet size and spheroidal shape are determined by using an image analysis system. By using digital camera photomicrographs can be obtained where further analysis of the obtained pellet images is carried out by software (Digimizer, USA).

Therefore, characterization each individual pellet can be known by the aspect ratio (AR) and two-dimensional shape factor(eR). The equation for pellet sphericity is as follows:

$\mathrm{eR}=2 \pi \mathrm{r} / \mathrm{Pm}-(\mathrm{b} / \mathrm{l}) 2$

Where ' $r$ ' is the radius, ' $\mathrm{Pm}$ ' is the perimeter, ' $\mathrm{l}$ ' is the length and ' $\mathrm{b}$ ' is the width of the pellet.

- Compatibility studies [16]: It plays important role in selecting the appropriate excipients for a particular drug and a particular formulation because the drug maintains its continuous contact with one or more excipients which directly or indirectly may affect the stability of drug or a formulation. These compatibility studies can be carried out by using FT-IR Spectrophotometer and Differential Scanning Calorimetry.

- FTIR studies [18]: FTIR stands for Fourier transform infrared spectroscopic, where the analysis is used for pure drug and pellet grains using $\mathrm{KBr}$ pellet process on FTIR spectrometer. The drug is mixed with $\mathrm{KBr}$ and spectra are taken. FTIR spectrum of pure drug is compared with FTIR spectra of drug formulations. The disappearance of peaks or shifting of peaks in any of the spectra can be studied by using the apparatus named FTIR 8400-S, Shimadzu, Japan model.

\section{Evaluation of pellets}

- Percentage yield [17]: Percentage yield determination is carried out to know the preparation procedure chosen for pellet formation is effective or not, and also to know the importance of the procedure used regarding safety and efficacy with lesser effort and greater benefit. Hence the quantity or the amount of active pharmaceutical ingredients, polymers, binding agent, anti-frictional agents, starch paste and other process parameters are the factors which play a major role in deciding the yield of the pellets during pelletization process.

The formula for calculation of $\%$ yield of a pellet is written below:

$\%$ yield $=$ weight of pellets $/$ Weight of drug+weight of polymers $\times 100$

- Loose surface crystal study (LSC) [17]: A total amount of $200 \mathrm{mg}$ of pellets are suspended in a beaker containing $100 \mathrm{ml}$ of phosphate buffer ( $\mathrm{pH}$ 7.4). The amount of drug present in the solution can be analyzed by spectrophotometrically at $265 \mathrm{~nm}$.

- Determination of drug content [19]: Pellets drug content can be determined using UV/Visible spectrophotometer instrument were the prepared pellets are crushed into powder form. And the finely crushed sample of pellets equivalent to $100 \mathrm{mg}$ of DPP is transferred to $100 \mathrm{ml}$ volumetric flask which is diluted with $100 \mathrm{ml}$ solvent which is particular for particular pellet particles and the absorbance value is noted at suitable wavelength, where initially before placing sample the background scan has to done and the drug content in pellet is determined using calibration curve.

- Surface Morphology [19]: Scanning electron microscopy method is used to determine the surface morphology of formed pellets and also the cross-section pattern of pellets can be known. Some researcher analyzed surface roughness of pellet can be done by applying a non-contracting laser profile meter. And also by using an optical microscope the microstructure of spheroidal particles surface can be determined. 
- Specific Surface Area4: Specific surface area totally depends upon the size and the shape of the pellet granules and if the coated pellets are available then a desirable surface area can be achieved. The information regarding uncoated pellets plays a key role in increasing drug release by surface area. Thus specific surface area of a pellet is carried out by "Gas adsorption technique".

- In vitro drug release studies: In vitro dissolution studies are carried out either by using paddle type or basket type apparatus using IP or USP model. According to the IP model, type 1 is a paddle and type 2 is basket apparatus and according to the USP model, type 1 is basket and type 2 is paddle [18]. $900 \mathrm{ml}$ of a solution which is suitable for the formulation is used as a dissolution medium. The paddles or basket is operated at a particular rpm based upon the drug, and the temperature has to be maintained at $37{ }^{\circ} \mathrm{C} \pm 0.5{ }^{\circ} \mathrm{C}$ throughout the experiment. Dissolution samples should be withdrawn from the apparatus at regular intervals of a time period starting from minutes to hours up to $24 \mathrm{~h}$ based on the type of drug delivery pattern and meanwhile replacement of equal volume of dissolution medium to maintain the volume throughout the experiment so that constant sink condition is achieved. Then further step is to dilute the withdrawn samples at a different interval of time with same dissolution media used and the amount of drug released was estimated by using "UV-Spectrophotometer" at suitable wavelength depending upon drug used [20].

\section{CONCLUSION}

In present scenario, pelletization technology in pharmaceutical industry has obtained a prominent role due to its different extent character in novel drug delivery system as well as in conventional system and also incompatible drugs can also be prepared by overtaking granulation process. Pellets can be formulated using various technique but widely used is "Extrusion Spheronization" technique because of its fast working process without complicated design and high efficiency of pellets production with uniform spherical particles.

\section{AUTHORS CONTRIBUTIONS}

All the author have contributed equally

\section{CONFLICT OF INTERESTS}

Declare none

\section{REFERENCES}

1. Ahir AA, Hajare AA, Bhagwat DA. Pelletization technology: methods and applications-a review pelletization technology: methods and applications-a review. Res J Tech 2015;8:131-8.

2. Jawahar N, Anilbhai PH. Pellets for multi-unit particulates systems (MUPS): a novel oral dosage forms. J Pharm Sci Res 2012;4:1915-23.
3. Ratul D, Baquee AA. Pellets and pelletization techniques: a critical review. Int Res J Pharm 2013;4:90-5.

4. S Ramu, G Ramakrishna, M Balaji, K Kondala Rao, S Haranadh Reddy, D Pava kumar. Multiple unit drug delivery systems: pelletization techniques. Am J Adv Drug Delivery 2013;1:11-21.

5. T VK, Reddy MS. Formulation and evaluation ofenteric coated pellets of rifampicin and isoniazid with improved rifampicin stability. Asian J Pharm Clin Res 2014;7:154-6.

6. Raju Onkar Sonawane, Savita Dattatraya Patil. Formulation aspects and effect of critical factors for designing extended formulation aspects and effect of critical factors for designing extended release pellets: an updated review. Taylor Fr 2016;55:976-89.

7. Supriya P, Rajni B, Rana AC. Review article pelletization techniques: a literature review. Int Res J Pharm 2012;3:43-7.

8. Srinivasarao K, Jyothirmai KSL, Rao NR. Pellets and pelletization techniques: a review. Int J Res Pharm Chem 2017;7:141-7.

9. Politis SN, Rekkas DM. Pelletization processes for pharmaceutical applications: a patent review. Recent Pat Drug Delivery Formulation 2011;5:61-78.

10. Muley S, Nandgude T, Poddar S. Extrusion-spheronization a promising pelletization technique: in-depth review. Asian J Pharm Sci 2016;11:684-99.

11. Bhaskaran S, Lakshmi PK. Extrusion spheronization-a review. Int J PharmTech Res 2010;2:2429-33.

12. Mircea Hirjau MD, Anca Cecilia Nicoara, MD VH. Pelletization techniques used in pharmaceutical fields. Pract Farm 2011;4:206-11.

13. Gupta AM, Shivhare UD, Suruse PB. International journal of pharmaceutical and different aspects of pellets formulation and their evaluation. Int J Pharm Phytopharm Res 2015;4:331-6.

14. Verma A. Pharmaceutical pellets: a versatile carrier for oral controlled delivery of drugs. Indian J Pharm Educ 2016;50:8-24.

15. Sachdeva V, Alam S, Kumar R, Kataria MK. Oral multiunit pellet extended release dosage form: a review. Int Curr Pharm J 2013;2:177-84.

16. Ravella VN, Nadendla RR, Kesari NC. Design and evaluation of sustained release pellets of aceclofenac. JOPR J Pharm Res 2013;6:525-31.

17. Bathool A, Gowda DV, Khan MS. Development and evaluation of porous membrane pellets of disopyramide phosphate for sustained release. Asian J Pharm 2012;12:107-15.

18. Karra N, Raju N. Formulation and evaluation of torsemide pellets for extended drug release by extrusion-spheronization method. Asian J Pharm 2018;12:5-6.

19. Kalyani C, Reddy KV, Rao EA, Kumari MP. Formulation and in vitro evaluation of metoprolol succinate extended release pellets. Br Biomed Bull 2013;1:73-82.

20. Gandhi R, Ashokraj Y, Kaul CL, Panchagnula R. Using extrusionspheronization to develop controlled-release formulations of azithromycin. Pharmtech Com 2005;1:68-86. 